\title{
HERMENÊUTICA, ANALÍTICA E \\ ARGUMENTAÇÃO: DISTINTAS VISÕES SOBRE A \\ DISCRICIONARIEDADE JUDICIAL
}

\section{HERMENEUTICS, ANALYTICS AND ARGUMENTATION: DIFFERENT VIEWS ON JUDICIAL DISCRETION \\ HERMENÉUTICA, ANALÍTICA Y ARGUMENTACIÓN: DISTINTAS VISIONES SOBRE LA DISCRECIONALIDAD JUDICIAL}

\section{Lenio Luiz Streck ${ }^{1}$}

Licença CC BY:

Artigo distribuído sob os termos Creative Commons, permite uso e distribuição irrestrita em qualquer meio desde que o autor credite a fonte original.

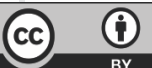

\begin{abstract}
Resumo:A crise que atravessa a hermenêutica jurídica possui uma relação direta com a discussão acerca da crise do conhecimento e do problema da fundamentação, própria do início do século XX. Observam-se as várias tentativas de estabelecer regras ou cânones para o processo interpretativo a partir do predomínio da objetividade ou da subjetividade ou, até mesmo, de conjugar a subjetividade do intérprete com a objetividade do texto. Apesar da revolução copernicana produzida pela viravolta linguístico-hermenêutica, é possível detectar nitidamente a sua não recepção pela hermenêutica jurídica praticada nas escolas de direito e nos tribunais, onde ainda predomina o método, mesmo que geneticamente modificado pelas teorias discursivas.
\end{abstract}

Palavras-chave: Hermenêutica; Analítica; Argumentação; Discricionariedade judicial.

Abstract: The crisis that affects juridical hermeneutics is directly related to the discussion of the crisis of knowledge and the problem of establishing a legal framework, typical of the beginning of the Twentieth century. This work notes the various attempts to establish rules or canons for the process of interpretation based on the predominance of objectivity or subjectivity, or even to combine the subjectivity of the interpreter with the objectivity of the text. Despite the Copernican revolution produced by the linguistic-hermeneutical turn of events, it is possible to clearly detect its non-reception by legal hermeneutics practiced in law schools and courts, where the method still predominates, albeit genetically modified by discursive theories.

Keywords: Hermeneutics; Analytical; Argumentation; Judicial discretion.

Resumen: La crisis que atraviesa la hermenéutica jurídica posee una relación directa con la discusión acerca de la crisis del conocimiento y del problema de la fundamentación, propia del inicio del siglo XX. Se

Mestre e Doutor em Direito pela Universidade Federal de Santa Catarina. Pós-doutor pela Universidade de Lisboa. Professor titular do Programa de Pós-Graduação em Direito (Mestrado e Doutorado) da UNISINOS e da UNESA-RJ; Professor visitante da Universidade Javeriana-Bogotá; Membro catedrático da Academia Brasileira de Direito Constitucional ABDConst; Coordenador do DASEIN Núcleo de Estudos Hermenêuticos. Ex-Procurador de Justiça do Estado do Rio Grande do Sul. Advogado. 


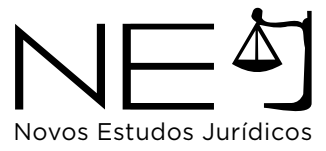

observan varios intentos de establecer reglas o cánones para el proceso interpretativo a partir del predominio de la objetividad o de la subjetividad o, hasta mismo, de conjugar la subjetividad del intérprete con la objetividad del texto. A pesar de la revolución copernicana producida por el giro linguístico hermenéutico, es posible detectar nítidamente su no recepción por la hermenéutica jurídica practicada en las escuelas de derecho y en los tribunales, donde todavia predomina el método, mismo que genéticamente modificado por las teorías discursivas.

Palabras clave: Hermenéutica; Analítica; Argumentación; Discrecionalidad judicial.

\section{INTRODUÇÃO}

Na história moderna, tanto na hermenêutica teológica como na hermenêutica jurídica a expressão tem sido entendida como arte ou técnica (método), com efeito diretivo sobre a lei divina e a lei humana. Johann Conrad Dannhauer, teólogo de Estrasburgo, introduziu, em 1564, o termo "hermenêutica" para substituir a "hermenêutica como ars interpretandi"2.

Importa lembrar que o ponto comum entre a hermenêutica jurídica e a hermenêutica teológica reside no fato de que, em ambas, sempre houve uma tensão entre o texto proposto e o sentido que alcança a sua aplicação na situação concreta, seja em um processo judicial ou em uma pregação religiosa. Essa tensão entre o texto e o sentido a ser atribuído ao texto coloca a hermenêutica diante de vários caminhos, todos ligados, no entanto, às condições de acesso do homem ao conhecimento acerca das coisas.

Assim, ou se demonstra que é possível colocar regras que possam guiar o hermeneuta no ato interpretativo, mediante a criação, v.g., de uma teoria geral da interpretação; ou se reconhece que a pretensa cisão entre o ato do conhecimento do sentido de um texto e a sua aplicação a um determinado caso concreto não são de fato atos separados; ou se reconhece, finalmente, que as tentativas de colocar o problema hermenêutico a partir do predomínio da subjetividade do intérprete ou da objetividade do texto não passa(ra)m de falsas contraposições fundadas no metafísico esquema sujeito-objeto.

A crise que atravessa a hermenêutica jurídica possui uma relação direta com a discussão acerca da crise do conhecimento e do problema da fundamentação, própria do início do século XX. Hermenêutica foi sendo transformada em um termo "da moda", quase um enunciado performativo. Sua simples invocação já lembra, para os juristas imersos no senso comum teórico, uma espécie de "libertação das amarras do positivismo exegético", ignorando, inclusive, as diversas formas de positivismo pós-exegético que se formaram pós-Hart³ ${ }^{3}$ Efetivamente, é possível dizer que o termo 
"hermenêutica" sofre de anemia significativa - expressão cunhada por Luis Alberto Warat - mormente se se levar em conta a sua apropriação pelo pensamento contemporâneo e "pós-moderno-relativista".

Com efeito, este é um dos sentidos possíveis do termo, como lembra Jean Grondin4: designar um espaço cultural e intelectual onde não há verdade, porque "tudo é uma questão de interpretação". Esse tipo de tese encontrou em Nietzsche a sua versão mais forte: "fatos não há; só há interpretações". Mas esse não deve ser o sentido mais adequado para aquilo que a hermenêutica sempre quis ser: "uma doutrina da verdade no campo da interpretação"5. Desde a hermenêutica clássica até os nossos dias, a hermenêutica passou por profundas transformações, que somente podem ser bem compreendidas se vistas a partir dos paradigmas filosóficos.

Observe-se que as várias tentativas de estabelecer regras ou cânones para o processo interpretativo a partir do predomínio da objetividade ou da subjetividade ou, até mesmo, de conjugar a subjetividade do intérprete com a objetividade do texto, ${ }^{6}$ não resistiram às teses da viragem ontológico-linguística (Heidegger-Gadamer), superadoras do esquema sujeito-objeto, compreendidas a partir do caráter ontológico prévio do conceito de sujeito e da desobjetificação provocada pelo círculo hermenêutico e pela diferença ontológica.

A viragem hermenêutico-ontológica, provocada pela publicação de Sein und Zeit ${ }^{7}$ por Martin Heidegger, em 1927, e a publicação, anos depois, de Wahrheit und Methode, por Hans-Georg Gadamer, em 1960, foram fundamentais para um novo olhar sobre a hermenêutica jurídica. A partir dessa ontologische Wendung (giro ontológico), inicia-se o processo de superação dos paradigmas metafísicos objetivista aristotélico-tomista e subjetivista (filosofia da consciência) que sustentam as diversas concepções acerca do direito e de sua interpretação.

Nesse sentido, é de fundamental importância destacar que tanto Heidegger, Wittgenstein e Gadamer foram os corifeus da libertação da filosofia da mão de ferro do racionalismo moderno, nas palavras de Charles Taylor. ${ }^{9}$ Essa libertação, que não está ainda terminada, é feita de muitos sofrimentos e sempre está sob a ameaça da reversão. Essa ameaça vem da "concepção dominante do agente pensante", um agente desprendido como ocupante de uma sorte de protovariante da "visão a partir do nada", na sugestiva frase de Thomas Nagel. ${ }^{10}$

GRONDIN, Jean. Hermenêutica. Tradução de Marcos Marcionilo. São Paulo: Parábola Editorial, 2012.

Idem. p. 9 e seguintes.

Nesse sentido, apontam-se contradições na teoria de Michelle Taruffo, famoso jusfilósofo do direito processual. Ao mesmo tempo em que propugna por verdade adequacional, advoga o reforço do protagonismo do juiz como único sujeito capacitado para descobrir o que realmente aconteceu no caso concreto (STRECK, Lenio Luiz. Processo Judicial como Espelho da Realidade? Notas Hermenêuticas à Teoria da Verdade em Michele Taruffo. Sequência, v. 37, p. 115-136, 2016).

7 HEIDEGGER, Martin. Sein und Zeit. 17. ed. Tübingen: Max Niemayer, Verlag Tübingen, 1993.

8 GADAMER, Hans-Georg. Wahrheit und Methode l: Grundzüge einer philosophischen Hermeneutik. Tübingen: J.C.B. Mohr (Paul Siebeck), 1990.

9 TAYLOR, Charles. Philosophical Arguments. New York, Harvard University Press, 1995

10 NAGEL, Thomas. The view from nowhere. Oxford: Oxford University Press, 1986. 
$\mathrm{Na}$ realidade, as diversas variantes do pensamento moderno, sustentadas nesse agente pensante, buscam fazer um "modelo de nós mesmos como agentes pensantes", de onde se pode dizer que o Selbstsüchtiger, o sujeito solipsista, é a figura mais presente no campo da interpretação do direito na contemporaneidade. Aqui, inclusive, cabe uma reflexão sobre a própria tradução "literal" da expressão alemã como "sujeito viciado em si". Isso tudo levou a diversas elaborações de teses sobre a interpretação do direito, tendo como ponto fulcral a tentativa de superar o positivismo exegético. Daí a chegar no ceticismo interpretativo (ou a uma hermenêutica ceticista) foi um passo, uma vez que essa problemática já se colocara nas diversas teses que buscaram superar as diversas formas de positivismo do século XIX (positivismo exegético francês, o pandectismo alemão e a jurisprudência analítica inglesa) ${ }^{11}$. Alie-se a isso um surto de pós-modernidade que ingressou no direito, nele colocando uma espécie de "ontologia negativa", a partir da tese nietzscheana da vontade do poder (Wille zur Macht). Como alertou Taylor ${ }^{12}$, parece que se está ainda sob a ameaça do paradigma que se busca superar ou o que mais especialmente autores como Heidegger, Wittgenstein e Gadamer buscaram fazer. Pensa-se que o nosso receio está na seguinte equação construída pelo paradigma da filosofia da consciência e suas derivações: como se vê o mundo a partir da projeção do sujeito, aí está a razão da existência do ceticismo (ou da hermenêutica da suspeita, para aproveitar a expressão de Grondin quando opõe a hermenêutica da confiança de Gadamer à hermenêutica da suspeita de Nietszche, Freud, Marx, entre outros).

No plano das práticas jurídicas e da doutrina jurídica - especialmente a brasileira -, é possível perceber certa imbricação, consciente ou inconsciente, dos paradigmas metafísicos clássico e moderno. Trata-se, pois, de um problema paradigmático. Alguns autores colocam na consciência do sujeito-juiz o locus da atribuição de sentido (solipsista), como, por todos, Maria Helena Diniz, ${ }^{13}$ para quem "conhecer é trazer para o sujeito algo que se põe como objeto", consistindo, assim, "em levar para a consciência do sujeito cognoscente algo que está fora dele (...) tornando-o presente à inteligência". Nesse contexto, "filosofia da consciência" e "discricionariedade judicial" são faces da mesma moeda, valendo citar, v.g., nessa linha, Ernane Fidélis dos Santos, ${ }^{14}$ que sustenta que "não há nada que a ele [juiz] se sobreponha. Nem a própria lei (...). No direito constitucional, Uadi Bulos ${ }^{15}$ diz que o intérprete é aquele que "desvenda o significado das palavras normadas, esmiuçandoIhes a essência"; também Tourinho Filho, ${ }^{16}$ para quem o juiz, por meio da sentença, "declara o que sente". Trilhando por outros caminhos, juristas ligados a diversas teorias críticas - portanto, incomparavelmente avançados em relação às posturas dogmático-exegéticas - parecem, entretanto,

\footnotetext{
11 Para um estudo mais aprofundado do tema, ver STRECK, Lenio Luiz. Dicionário de hermenêutica: quarenta temas fundamentais da Teoria do Direito à luz da Crítica Hermenêutica do Direito. Belo Horizonte: Casa do Direito, 2017, pp. 166-176.

Idem, ibidem.

DINIZ, Maria Helena. Compêndio de Introdução à Ciência do Direito. São Paulo: Saraiva, 1998. p. 12 e segs.

DOS SANTOS, Ernane Fidélis. Manual de Direito Processual Civil. Vol. 1. 11. ed. São Paulo: Saraiva, 2006. p. 12.

BULOS, Uadi L. Manual de Interpretação Constitucional. São Paulo: Saraiva, 1997. p. 434.

TOURINHO FILHO, Fernando da Costa. Processo Penal. 23. ed. São Paulo: Saraiva. 2002. p. 125.
} 
incorrer, em momentos bem definidos, no mesmo paradigma da subjetividade, valendo referir Rui Portanova, para quem "o juiz é livre para basear seu convencimento tanto naquilo que as partes fazem (ativamente) no processo, como naquilo que elas deixam de fazer"17. Também em uma linha crítica, embora rejeitem qualquer filiação à filosofia da consciência, Ana Paula Barcellos e Luis Roberto Barroso ${ }^{18}$ aceitam a discricionariedade como componente indispensável para solucionar "casos difíceis". Já Rogério Gesta Leal, ${ }^{19}$ ainda que fundamente suas posições na teoria do discurso habermasiana, termina por defender a discricionariedade judicial, fazendo-o com apoio justamente em Herbert Hart. No direito alienígena, Alejandro Nieto ${ }^{20}$ faz uma profissão de fé no realismo jurídico em seu El arbítrio judicial, juntando os ingredientes da discricionariedade positivista com o paradigma subjetivista. Também Mauro Cappelletti ${ }^{21}$ atribui poderes discricionários ao juiz. Nem mesmo Mirreile Delmas-Marty ${ }^{22}$ consegue superar o paradigma representacional e suas consequências na teoria do direito, o que se pode perceber em seu Por um direito comum. Outros juristas preferem filiar-se às antigas teses formalistas, como, por todos, Damásio de Jesus, Magalhães Noronha e Frederico Marques (frise-se que autores como Fernando Capez, na linha de J.F. Mirabette, sustentam, ainda hoje, que a interpretação deve buscar a vontade da lei, desconsiderando de quem a fez - sic - e que "a lei terminada independe de seu passado, importando apenas o que está contido em seus preceitos". Já Caio Mário da Silva Pereira ${ }^{23}$ preferiu fazer uma simbiose entre objetivismo e subjetivismo, embora mais simpático à primeira tese, ao sustentar que o legislador se exprime por palavras, e é no entendimento real destas que o "intérprete investiga a sua vontade". Mais recentemente, cabe citar as visões sobre verdade de processualistas brasileiros, das quais pretendem extrair perigosas consequências práticas. Nesse sentido, Luís Guilherme Marinoni24 insiste na interpretação jurídica como ato de vontade. Junto a Daniel Mitidiero e Sérgio Arenhardt ${ }^{25}$, defende o papel dos Tribunais Superiores como "Cortes de Vértice" que fixariam sentidos para as demais, criando precedentes de maneira prospectiva ${ }^{26}$. Isso para não falar em sua defesa do livre convencimento motivado ${ }^{27}$, mesmo com sua retirada na redação do CPC/2015.

17 PORTANOVA, Rui. Princípios do Processo Civil. 3. ed. Porto Alegre: Livraria do Advogado, 1999. p. 245.

18 BARROSO, Luis Roberto; BARCELLOS, Ana Paula de. O Começo da história: a nova interpretação constitucional e o papel dos princípios no direito brasileiro. Rio de Janeiro: Renovar, 2003. p. 315.

19 LEAL, Rogério Gesta. O Estado-Juiz na Democracia Contemporânea - uma perspectiva procedimentalista. Porto Alegre: Livraria do Advogado, 2007. p. 96.

20 NIETO, Alejandro. El arbítrio judicial. Barcelona: Ariel, 2000. p. 28 e segs.

21 CAPPELETTI, Mauro. Juízes legisladores? Porto Alegre: Fabris, 1993. p. 33.

22 DELMAS-MARTY, Mirreile. Por um Direito Comum. São Paulo: Martins Fontes, 2004.

23 PEREIRA, Caio Mário da Silva. Instituições de Direito Civil, volume I. 12. ed. Forense, 1990. p. 135.

24 MARINONI, Luiz Guilherme. O STJ como Corte de Precedentes: recompreensão do sistema processual da Corte Suprema. São Paulo: Revista dos Tribunais, 2013, p. 156.

25 MARINONI, Luiz Guilherme; MITIDIERO, Daniel; ARENHART, Sérgio Cruz. O novo processo civil. São Paulo: Revista dos Tribunais, 2015.

26 Para uma crítica aos referidos autores, ver STRECK, Lenio Luiz. Precedentes Judiciais e Hermenêutica: o sentido da vinculação no CPC/2015. Salvador: Editora JusPodivm, 2018.

27 MARINONI, Luiz Guilherme; ARENHART, Sérgio Cruz; MITIDIERO, Daniel. Novo Código de Processo Civil comentado. São Paulo: Revista dos Tribunais, 2015, p. 392. 
De todo modo, mesmo hoje, em plena era do tão festejado ontological turn, de um modo ou de outro, continua-se a reproduzir o velho debate "formalismo-realismo". Mais ainda, e na medida em que o direito trata de relações de poder, tem-se, na verdade, em muitos casos, uma mixagem entre posturas "formalistas" e "realistas", isto é, por vezes, a "vontade da lei" e a "essência" da lei devem ser buscadas com todo o vigor; em outras, há uma ferrenha procura pela solipsista "vontade do legislador"; 28 finalmente, quando nenhuma das duas orientações é "suficiente", põese no topo a "vontade do intérprete", colocando-se em segundo plano os limites semânticos do texto, fazendo soçobrar até mesmo a Constituição. O resultado disso é que aquilo que começa com uma subjetividade "criadora" de sentidos (afinal, quem pode controlar a "vontade do intérprete"?, perguntariam os juristas), acaba em decisionismos e arbitrariedades interpretativas, isto é, em um "mundo jurídico" em que cada um interpreta como (melhor) lhe convém! Enfim, o triunfo do sujeito solipsista, o Selbstsüchtiger ${ }^{29}$.

Percebe-se, assim, que a hermenêutica jurídica praticada no plano da cotidianidade do direito deita raízes na discussão que levou Gadamer a fazer a crítica ao processo interpretativo clássico, que entendia a interpretação como sendo produto de uma operação realizada em partes (subtilitas intelligendi, subtilitas explicandi, subtilitas applicandi, isto é, primeiro compreendo, depois interpreto, para só então aplicar) ${ }^{30}$.

A impossibilidade dessa cisão - tão bem denunciada por Gadamer - implica a impossibilidade de o intérprete "retirar" do texto "algo que o texto possui-em-si-mesmo", numa espécie de Auslegung, como se fosse possível reproduzir sentidos; ao contrário, para Gadamer, fundado na hermenêutica filosófica, o intérprete sempre atribui sentido (Sinngebung). Mais ainda, essa impossibilidade da cisão - que não passa de um dualismo metafísico - afasta qualquer possibilidade de fazer "ponderações em etapas", circunstância, aliás, que coloca a(s) teoria(s) argumentativa(s) como reféns do paradigma do qual tanto tentam fugir: a filosofia da consciência. O acontecer da interpretação ocorre a partir de uma fusão de horizontes (Horizontenverschmelzung), porque compreender é sempre o processo de fusão dos supostos horizontes para si mesmo ${ }^{31}$.

\footnotetext{
28 Essa discussão sobre vontade da lei e vontade do intérprete deve ser examinada à luz da Crítica Hermenêutica do Direito. Nesse sentido, ver Streck, Lenio Luiz. Hermenêutica Jurídica e $(\mathrm{m})$ crise. 11. ed. Porto Alegre: Livraria do Advogado, 2014. p. 239 e seguintes, em que esse assunto é tratado amiúde.

29 Esse delineamento de autores e filiações teóricas pode ser encontrado em STRECK, Lenio Luiz. Verdade e Consenso: Constituição, hermenêutica e teorias discursivas. 6. ed. São Paulo: Saraiva, 2017.

30 GADAMER, Hans-Georg. Verdade e Método I: traços fundamentais de uma hermenêutica filosófica. 6. ed. Petrópolis: Vozes, 2004. p. 459 e seguintes.

31 Idem, Ibidem, p. 505 e seguintes.
} 


\section{A COMPLEXIDADE DA "QUESTÃO HERMENÊUTICA" E UMA CRÍTICA ÀS VISÕES MERAMENTE ANALÍTICAS DO FENÔMENO}

Veja-se, pois, como a "questão da hermenêutica jurídica" (crítica) é absolutamente complexa. Com efeito, vista de "fora", a hermenêutica jurídica é, por vezes - ou não raras vezes -, subestimada, como se a problemática da interpretação do direito estivesse restrita à análise de vaguezas, ambiguidades, uso contextual ou à discussão sobre vontade da lei versus vontade do legislador (esse equívoco é cometido pelas diversas disciplinas "afins").

Do mesmo modo, há que se tomar cuidado com análises que não levam em conta o papel da Constituição (mormente no sentido de Constituição principiológica). Assim, como exemplo, vale referir a obra de Marcelo Dascal32, que, embora sofisticada no plano da compreensão e da interpretação no nível da comunicação, privilegia uma analítica da linguagem no campo do direito (na linha de autores como J. Wróblewski). Daí a insistência no papel da Constituição: pensa-se que não é o mesmo falar em interpretação do direito no interior de um sistema jurídico com papel reduzido para os princípios e para a jurisdição constitucional em um sistema com uma "baixa incidência" desses elementos. Também não se deve olvidar o estado da arte da doutrina e da jurisprudência de cada país, que conforma a "situação hermenêutica" do autor da respectiva teoria acerca da interpretação do direito.

Assim, parece insuficiente a descrição - ou prescrição - de Dascal, no sentido de que a interpretação judicial operativa ocorre no caso de dúvida devido à falta da clareza necessária ou da transparência requerida para a aplicação da lei, e que esse tipo de interpretação envolve sempre um componente pragmático:

\footnotetext{
A clareza não é um dado absoluto, nem como ponto de partida nem como ponto final da compreensão de um texto. Consequentemente, a linguagem legal tem de tolerar a existência da dúvida interpretativa, mesmo no que diz respeito à questão prévia de se um texto de ou não ser interpretado. ${ }^{33}$
}

Correta a observação de Dascal. Entretanto, isso é pouco para a interpretação do direito na contemporaneidade. Sequer constitui novidade. Para a teoria do direito, a partir de Hart - para dizer o mínimo -, a questão da linguagem é bem mais sofisticada que a antiga discussão sobre se a interpretação do direito deve ou não tolerar o ingresso do mundo prático na atribuição de sentido.

Na mesma linha - e aqui reforço as críticas a Dascal -, parece não haver dúvida de que o campo da interpretação do direito avançou para além de se dizer que "na ciência jurídica, ao lidar com a sistematização da lei em vigor, uma interpretação doutrinária também é necessária" (sic), ou

DASCAL, Marcelo. Interpretação e compreensão. Tradução de Marcia Heloisa Lima da Rocha. São Leopoldo, Unisinos. 2006.

Idem, ibidem, p. 360. 
que "o raciocínio da interpretação legal é uma das espécies do raciocínio jurídico", nele estando "subentendida a ideia de racionalidade". Embora o autor assuma que se espera que "uma decisão jurídica não seja arbitrária, isto é, que seja passível de ser justificada por 'boas razões'" - e isso é absolutamente elogiável -, mais adiante coloca a racionalidade como "justificabilidade da decisão". Ora, em um sistema jurídico no qual os princípios ingressam no direito para superar as insuficiências do mundo das regras, há fortes indicativos - advindos dos diversos modelos contemporâneos preocupados com a especificidade da interpretação do direito constitucional - que apontam como superada a dicotomia subjetivismo-objetivismos.

Em Dascal, entretanto, tudo está a indicar que a dicotomia persiste, quando, por exemplo, contenta-se com a existência de dois tipos básicos de "ideologia de interpretação" (sic), de acordo com o tipo de valores subjacentes que comportam: a ideologia estática favorece valores como certeza legal, segurança legal, previsibilidade legal e estabilidade da lei; a ideologia "dinâmica" está mais preocupada com a adaptação da lei às necessidades mutáveis da vida. Tais necessidades são tidas como a axiologia que fundamenta o contexto funcional da operação da lei na ocasião de sua interpretação (embora também tomem em consideração o contexto sistêmico). A ideologia estática corresponde à construção do significado como sendo o significado do emissor, tomado como idêntico à vontade do legislador histórico. A ideia de significado da ideologia dinâmica, por outro lado, é a do significado do emissor modificado, que pode ser alterado, embora não haja alteração na letra da lei.

Mais ainda, segundo o autor, há, na cultura jurídica dominante, diretrizes da interpretação jurídica aceitas tanto pela ideologia estática quanto pela dinâmica, ignorando que tal circunstância não constitui qualquer novidade na contemporânea teoria do direito. Essas ideologias seriam disfarçadas sob o título de "teorias da interpretação" (teoria subjetiva e teoria objetiva). Essas ideologias dependeriam, desse modo, implicitamente, "do ponto de vista tomado em relação ao legislador racional". ${ }^{44}$ Por tudo isso - e essa crítica pode ser estendida às diversas concepções interpretativo-analíticas do direito -, não se crê que as demandas da hermenêutica jurídica em tempos de Constitucionalismo Contemporâneo e de pós-positivismo (ou não positivismo) possam ficar reduzidas aos usos da linguagem, mesmo que se alegue, como Dascal, que a pragmática "deve ser lida não só com os usos comunicativos ou sociais da linguagem, mas também com os usos que são, de certo modo, puramente privados". Penso, ademais, que esse equívoco de importantes filósofos como Dascal é também cometido no âmbito das teorias argumentativas, que não deixam de ser teorias analítico-metodológicas, por objetivarem a construção de discursos de adjudicação sobre o direito, que, ao fim e ao cabo, substituem o próprio direito, reforçando o esquema sujeito-objeto.

34 DASCAL, Marcelo. Interpretação e compreensão. Tradução de Marcia Heloisa Lima da Rocha. São Leopoldo: Editora Unisinos, 2006. p. 342 e seguintes. 
Isso não significa afirmar (ou concluir) que tais análises feitas por esses importantes autores, jusfilósofos ou não (Dascal, Alexy, Aaulis Arnio, MacCormick, para falar apenas destes), estejam desvinculadas das pretensões hermenêuticas de realização dos direitos fundamentais-sociais na Sociedade Contemporânea. Ao contrário: a realização das promessas incumpridas da modernidade - as diversas teorias críticas (teoria do discurso habermasiana, as diversas teorias da argumentação, a hermenêutica filosófica, a metódica estruturante, etc.), todas perfeitamente inseridas no paradigma do Estado Democrático de Direito, têm, inequivocamente, um objetivo comum: a superação dos modelos interpretativos dogmáticos e dogmatistas que se enraizaram na doutrina e na jurisprudência do Direito, responsáveis em grande medida pela inefetividade da Constituição (circunstância que assume foros de dramaticidade em países como o Brasil).

\section{A(S) RESISTÊNCIA(S) DO MODUS INTERPRETATIVO DOMINANTE NA DOUTRINA E NA JURISPRUDÊNCIA: O ENTRECHOQUE ENTRE O NOVO E O VELHO}

Apesar da revolução copernicana produzida pela viravolta linguístico-hermenêutica, é possível detectar nitidamente a sua não recepção pela hermenêutica jurídica praticada nas escolas de direito e nos tribunais, onde ainda predomina o método, mesmo que geneticamente modificado pelas teorias discursivas. Tantos métodos e procedimentos interpretativos postos à "disposição" dos juristas fazem com que ocorra a objetificação da interpretação, porque possibilitam ao intérprete sentir-se desonerado de maiores responsabilidades na atribuição de sentido, colocando no fetichismo da lei e no legislador a responsabilidade das anomalias do direito. Ou, por outro lado, deslocam o polo de tensão da "letra da lei" para a vontade do intérprete, circunstância que apenas demonstra que o Direito navega dicotomicamente - no plano dos paradigmas filosóficos entre objetivismo e subjetivismo.

Neste ponto, aliás, reside o forte vínculo entre a hermenêutica metodológica e o positivismo jurídico, ${ }^{35}$ que assim se coloca refratário ao paradigma estabelecido pelo Constitucionalismo Contemporâneo. Resistente ao giro hermenêutico-ontológico, a hermenêutica jurídica vem possibilitando a sobrevivência das velhas teses positivistas (clássico-exegéticas) acerca da interpretação,

$35 \quad$ Entende-se o positivismo a partir de sua principal característica: a discricionariedade, que ocorre a partir da "delegação" em favor dos juízes para a resolução dos casos difíceis (não "abarcados" pela regra). O holding da discussão encontra-se nas críticas dirigidas à Herbert Hart por Ronald Dworkin, para quem o juiz não possui discricionariedade para solver os hard cases. Antes de tudo, trata-se de uma questão de democracia. Por outro lado, parece despiciendo acentuar ou lembrar que a crítica à discricionariedade judicial não é uma "proibição de interpretar". Ora, interpretar é dar sentido (Sinngebung). É fundir horizontes. E Direito é um sistema de regras e princípios, "comandado" por uma Constituição. Que as palavras da lei (lato sensu) contém vaguezas e ambiquidades e que os princípios podem ser - e na maioria parte das vezes são - mais "abertos" em termos de possibilidades de significado, não constitui nenhuma novidade. O que deve ser entendido é que a aplicação destes textos (isto é, a sua transformação em normas) não depende de uma subjetividade assujeitadora (esquema sujeito-objeto), como se os sentidos a serem atribuídos fossem fruto da vontade do intérprete, como que a dar razão a Kelsen, para quem a interpretação a ser feita pelos juízos é um ato de vontade (sic). O "drama" da discricionariedade aqui criticada é que esta transforma os juízes em legisladores. Isso enfraquece a autonomia do direito conquistada principalmente no paradigma do Estado Democrático de Direito. Nesse sentido, ver: STRECK, Lenio Luiz. Dicionário de hermenêutica: quarenta temas fundamentais da Teoria do Direito à luz da Crítica Hermenêutica do Direito. Belo Horizonte: Casa do Direito, 2017. 
como a subsunção, o silogismo, a individualização do Direito na "norma geral" a partir de "critérios puramente cognitivos e lógicos", a liberdade de conformação do legislador, a discricionariedade do poder executivo, assim como o papel da Constituição como estatuto meramente regulamentador do exercício do poder.

Por tais razões, assume absoluta relevância o rompimento paradigmático proporcionado pela CHD (Crítica Hermenêutica do Direito ${ }^{36}$ ) exatamente pela circunstância de que a hermenêutica jurídica não é uma simples ferramenta à disposição do usuário. A hermenêutica jurídica não pode ser apenas uma ferramenta para a organização do pensamento. A hermenêutica possui uma temática específica, dirá Gadamer ${ }^{37}$. Apesar de sua generalidade, não pode ser integrada legitimamente na lógica. Em certo sentido, partilha com a lógica a universalidade. Entretanto, em outro, supera-a. Portanto, na hermenêutica filosófica, a ferramenta não é decisiva, isto porque na linguagem existe algo muito além do enunciado, isto é, o enunciado não carrega em si mesmo o sentido, que viria a ser "desacoplado" pelo intérprete. Na interpretação sempre fica algo de fora, o não dito, o inacessível. É assim que "ser que pode ser compreendido é linguagem", dirá Gadamer ${ }^{38}$. Também não se pode confundir a hermenêutica jurídica com as teorias da argumentação jurídica ou qualquer teoria lógicoanalítica, as quais possuem nítido caráter procedimental, tratando, pois, de outra racionalidade, que é apenas discursiva. A teoria da argumentação jurídica - embora procure se colocar em oposição ao positivismo-normativista - não superou o esquema representacional sujeito-objeto, porque continua na busca de regras prévias (procedimentos) que possam conformar, de forma dedutiva, as decisões judiciais. E nisto não difere da metodologia positivista. Mais do que isso, na Teoria da Argumentação Jurídica mais conhecida, como a de Robert Alexy, é possível perceber fortes traços discricionaristas, como é o caso da ponderação de princípios. Sendo mais explícito: não há evidência na Teoria da Argumentação de que o intérprete tenha abandonado o discricionarismo, circunstância que o mantém,

A Crítica Hermenêutica do Direito, fundada por mim ao longo das obras Hermenêutica Jurídica e(m) crise e Verdade e Consenso, é uma espécie de cadeira assentada entre o paradigma objetivista clássico e da filosofia da consciência (e/ou de suas vulgatas voluntaristas). A CHD move-se nas águas da fenomenologia hermenêutica, pela qual o horizonte do sentido é dado pela compreensão (Heidegger) e ser que pode ser compreendido é linguagem (Gadamer), cuja linguagem não é simplesmente objeto, e sim horizonte aberto e estruturado e a interpretação faz surgir o sentido. O fato de as palavras da lei serem ambíguas (polifonia) não quer dizer que o processo hermenêutico admita discricionariedades e decisionismos. É possível encontrar respostas corretas em direito, conforme a criteriologia que se explicita em Jurisdição Constitucional e Decisão Jurídica (4. ed. São Paulo, Revista dos Tribunais, 2014). Com a CHD, busca-se apresentar um ferramental para a interpretação do direito. Para tal, usa-se como fio condutor o "método" fenomenológico, visto, a partir de Heidegger, como "interpretação ou hermenêutica universal", é dizer, como revisão crítica dos temas centrais transmitidos pela tradição filosófica através da linguagem, como destruição e revolvimento do chão linguístico da metafísica ocidental, mediante o qual é possível descobrir um indisfarçável projeto de analítica da linguagem, numa imediata proximidade com a práxis humana, como existência e faticidade, em que a linguagem - o sentido, a denotação - não é analisada num sistema fechado de referências, mas, sim, no plano da historicidade. Enquanto baseado no método hermenêuticolinguístico, o texto procura não se desligar da existência concreta, nem da carga pré-ontológica que na existência já vem sempre antecipada. A tarefa da CHD é a de desenraizar aquilo que tendencialmente se encobre. Fincada na matriz teórica originária da ontologia fundamental, busca, por meio de uma análise fenomenológica, o des-velamento (Unverborgenheit) daquilo que, no comportamento cotidiano, ocultamos de nós mesmos (Heidegger): o exercício da transcendência, no qual não apenas somos, mas percebemos que somos (Dasein) e somos aquilo que nos tornamos através da tradição (pré-juízos que abarcam a faticidade e historicidade de nosso ser-no-mundo, no interior do qual não se separa o direito da sociedade, isto porque o ser é sempre o ser de um ente, e o ente só é no seu ser, sendo o direito entendido como a sociedade em movimento), e onde o sentido já vem antecipado (círculo hermenêutico). Trata-se, enfim, da elaboração de uma análise antimetafísica - entendida a metafísica como ontoteologia (como explica Ernildo Stein) - isso porque a partir da viragem linguística e do rompimento com o paradigma metafísico aristotélico-tomista e da filosofia da consciência (e de suas vulgatas voluntaristas), a linguagem deixa de ser uma terceira coisa que se interpõe entre um sujeito e um objeto, passando a ser condição de possibilidade.

37 GADAMER, Hans-Georg. Verdade e Método I: traços fundamentais de uma hermenêutica filosófica. 6. ed. Petrópolis: Vozes, 2004.

38 Idem, ibidem, p. 687. 
mesmo negando, ligado à filosofia da consciência ${ }^{39}$. Portanto, o compreender não depende da instituição de uma "supervisão epistemológica" a ser realizada pelas teorias do (e sobre o) discurso jurídico de cariz procedimental (nos seus diversos matizes). Na verdade, tais teorias se colocam como guardiães de uma pretensa racionalidade instrumental, com o que se torna razoável afirmar que uma teoria da argumentação jurídica pode ser válida somente naquilo que ela pode servir de auxílio na justificação/explicitação do nível da racionalidade compreensiva (estruturante do sentido, o "como" hermenêutico) que desde sempre já operou no processo interpretativo. A compreensão e a aplicação não acontecem em "etapas". Elas simplesmente acontecem conjuntamente. Uma hermenêutica jurídica capaz de intermediar a tensão inexorável entre o texto e o sentido do texto não pode continuar a ser entendida como uma teoria ornamental do direito, que sirva tão somente para colocar "capas de sentido" aos textos jurídicos. No interior da virtuosidade do círculo hermenêutico, o compreender não ocorre por dedução. Consequentemente, o método (o procedimento discursivo) sempre chega tarde, porque pressupõe saberes teóricos separados da "realidade". Antes de argumentar, o intérprete já compreendeu. A compreensão antecede, pois, qualquer argumentação. Ela é condição de possibilidade.

Portanto, é equivocado afirmar, por exemplo, que o juiz primeiro decide, para só depois fundamentar; na verdade, ele só decide porque já encontrou, na antecipação de sentido, o fundamento (a justificação). E somente é possível compreender isto a partir da admissão da tese de que a linguagem não é um mero instrumento ou "terceira coisa" que se interpõe entre um sujeito (cognoscente) e um objeto (cognoscível). O "abismo gnosiológico" que "separa" o homem das coisas e da compreensão acerca de como elas são não depende - no plano da hermenêutica jus-filosófica - de pontes que venham ser construídas - paradoxalmente - depois que a travessia (antecipação de sentido) já tenha sido feita.

Daí a importância da pré-compreensão ${ }^{40}$, que passa à condição de possibilidade nesse novo modo de olhar a hermenêutica jurídica. Nossos pré-juízos que conformam a nossa pré-compreensão não são jamais arbitrários. Pré-juízos não são inventados; eles orientam no emaranhado da tradição, que pode ser autêntica ou inautêntica. Mas isto não depende da discricionariedade (ou, se se quiser, um ato de vontade) do intérprete e tampouco de um "controle metodológico". O intérprete não "domina" a tradição. Os sentidos que atribuirá ao texto não dependem de sua vontade, por mais

39 "Os direitos fundamentais não são um objeto passível de ser dividido de uma forma tão refinada que inclua impasses estruturais - ou seja impasses reais no sopesamento -, de forma a torná-los praticamente sem importância. Neste caso, então, existe uma discricionariedade para sopesar, uma discricionariedade tanto do legislativo quanto do judiciário". ALEXY, Robert. Teoria dos Direitos Fundamentais. Tradução de Virgílio Afonso da Silva. São Paulo: Malheiros, 2008, p. 611. Ver também: ALEXY, Robert. Teoria de la Argumentación Jurídica: Teoría de Discurso Racional como Teoria de la Fundamentación Jurídica. Madri: CEPC, 1997

40 Que não se confunde com subjetivismos. Refere-se apenas a um saber sustentador que possibilita qualquer compreensão. Longe de ficar confinado a um sujeito, pode-se dizer que tal saber é aberto no passado (em uma tradição compartilhada) e no futuro (na fusão de horizontes pelo diálogo). Em Verdade e Consenso (Op. Cit.), discutem-se longamente as leituras equivocadas que se fazem de Gadamer, especialmente no âmbito jurídico. 


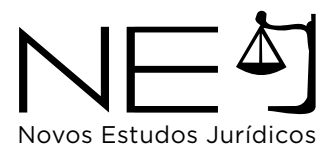

que assim queiram os adeptos do (metafísico) esquema representacional sujeito-objeto. O processo unitário da compreensão, pelo qual interpretar é aplicar (applicatio) - que desmitifica a tese de que primeiro conheço, depois interpreto e só depois eu aplico (veja-se, assim, o equívoco das teses que sustentam a possibilidade de "ponderações em fases ou etapas"), transforma-se em uma espécie de blindagem contra as opiniões arbitrárias. A interpretação jamais se dará em abstrato, como se a lei (o texto) fosse um objeto cultural. Há, sempre, um processo de concreção, que é a applicatio, momento do acontecer do sentido, que ocorre na diferença ontológica. Não há textos sem normas; não há normas sem fatos. Não há interpretação sem relação social. É no caso concreto que se dará o sentido, que é único; irrepetível.

\section{CONSIDERAÇÕES FINAIS}

Numa palavra final, uma reflexão crítica sobre a aplicação do direito não pode, pois, abrir mão dos pressupostos hermenêuticos que apontam para a superação do esquema sujeito-objeto, assim como dos diversos dualismos próprios dos paradigmas metafísicos objetificantes (clássico e da filosofia da consciência). É preciso insistir nisso. Ser e dever ser, consciência e mundo, linguagem e objeto, sentido e percepção, teoria e prática, texto e norma, vigência e validade, regra e princípio, casos simples e casos difíceis, discursos de justificação e discursos de aplicação: esses dualismos se instalaram no nosso imaginário sustentados pelo esquema sujeito-objeto.

Não se quer dizer, entretanto, que as diversas teorias do direito não estejam preocupadas em buscar respostas ao problema da crise paradigmática que atravessa o direito. Mas, nessa busca de soluções para os problemas da metodologia do direito, o que não se pode fazer é

"mixar" teorias, principalmente entre posturas procedimentais-argumentativas e perspectivas conteudísticas-ontológicas, para citar apenas estas. Permito-me, nesse sentido, lançar doze pontos que deixam nítida essa impossibilidade de mixagens metodológicas:

Primeiro: não se pode confundir hermenêutica com teoria da argumentação jurídica, isto é, hermenêutica não é similar a nenhuma teoria da argumentação (portanto, não é possível com ela fundir - por mais sofisticadas e importantes que sejam - as teses de Alexy, Atienza, Günther, para falar apenas destes);

Segundo, quando se diz que a Constituição e as leis são constituídas de plurivocidades sígnicas (textos "abertos", palavras vagas e ambíguas, etc.), tal afirmativa não pode dar azo a que se diga que sempre há várias interpretações e, portanto, que o direito permite múltiplas respostas, circunstância que, paradoxalmente, apenas denuncia - e aqui chamo à colação as críticas de Dworkin à Hart - as 
posturas positivistas que estão por trás de tais afirmativas; como bem lembra Zaccaria, ${ }^{41}$ o significado a ser atribuído a um texto jurídico não pode reduzir-se ao que o autor-intérprete quer e nem ao que o receptor captou segundo seus próprios critérios, porque isto suporia a existência de um subjetivismo destruidor da juridicidade;

Terceiro: quando, por exemplo, com o seu Wahrheit und Methode, Gadamer confronta o método, não significa, sob qualquer hipótese, que a hermenêutica seja relativista e permita interpretações discricionárias/arbitrárias. Pelo contrário, Gadamer pretende demonstrar que existem verdades para além do método;

Quarto: quando se fala na invasão da filosofia pela linguagem, mais do que a morte do esquema sujeito-objeto, isso fundamentalmente quer dizer que não há mais um sujeito que assujeita o objeto (subjetivismos/axiologismos que ainda vicejam no campo jurídico) e tampouco objetivismos; em outras palavras, o giro linguístico-ontológico decretou a derrota do sujeito solipsista; nem o texto é tudo e nem o texto é nada;

Quinto: quando se popularizou a máxima de que "interpretar é aplicar" e que "interpretar é confrontar o texto com a realidade" não significa poder afirmar que texto e realidade sejam coisas que subsistam por si só ("fatos" desnudos) ou que sejam "apreensíveis" isoladamente (ou por etapas ou fases), sendo equivocado pensar, portanto, que interpretar é algo similar a "fazer acoplamentos entre um texto jurídico e os fatos" ou, como numa metáfora que circula nas salas de aula, "entre um parafuso e uma porca" (sic), em que o parafuso seria o texto, e a porca, a realidade, sendo a aplicação, ipso facto, o resultado dessa "junção";

Sexto: de igual maneira, quando se popularizou a assertiva de que "texto não é igual à norma" e que "a norma é o produto da interpretação do texto" - questão para a qual até mesmo alguns setores da dogmática jurídica tradicional já se atentaram -, nem de longe isso pode significar que "o texto não vale nada" ou que "norma e texto" sejam "coisas à disposição do intérprete", ou, ainda, que depende do intérprete a "fixação da norma";

Sétimo: se texto e norma não são a mesma coisa, tal circunstância não implica - sob pena do absurdo - a afirmação de que estejam separados (cindidos) ou que o texto contenha a própria norma, mas, sim, que apenas há uma diferença (ontológica) entre os mesmos; é preciso compreender que a norma é o texto em forma de enunciados, em que o conteúdo veritativo não é nada mais do que a dimensão predicativa, isto é, aquilo que se diz sobre ele. Ora, deixemos o texto nos dizer algo, como diria Gadamer. Se a CHD sustenta que há uma diferença entre texto e norma, significa, logicamente, que existem muitas semelhanças. Não há um desacoplamento completo. Não faz sentido discutir a

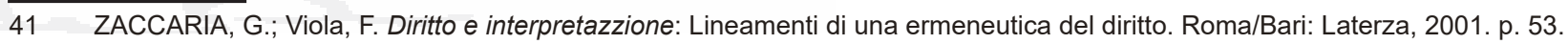


diferença de algo se não há uma série de semelhanças que turvam a identificação de uma ou outra coisa. Pode-se discutir a diferença que há entre um iate e um barco pesqueiro, mas ninguém discutira a diferença entre um iate e um caminhão. No nosso dia a dia somente se faz uso da palavra "diferença" quando, entre determinadas coisas, já existe uma similaridade tal qual que exija uma reflexão maior para que se perceba o que é uma coisa e o que é outra. Ou seja, reconhece-se a existência de uma série de semelhanças para se discutir as diferenças. É nesse sentido que a CHD sustenta a diferença entre texto e norma;

Oitavo: é um equívoco sustentar que o texto jurídico é apenas "a ponta do iceberg", e que a tarefa do intérprete é a de revelar o que está "submerso", porque pensar assim é dar azo à discricionariedade e ao decisionismo;

Nono: a fundamentação de decisões (pareceres, acórdãos, etc.) a partir de ementas jurisprudenciais (ou súmulas) sem contexto e verbetes protolexicográficos (ou enunciados aprovados em workshops jurídicos) apenas reafirma a vontade de os juristas de pretenderem fornecer respostas antes das perguntas, fazendo um retrocesso às teorias jurídicas do século XIX;

Décimo: as demandas da hermenêutica jurídica em tempos de Constitucionalismo Contemporâneo e de pós-positivismo (ou de não positivismo) não podem ficar reduzidas aos usos da linguagem, mesmo que se alegue, como Dascal, que a pragmática "deve ser lida não só com os usos comunicativos ou sociais da linguagem, mas também com os usos que são, de certo modo, puramente privados".

Decimo primeiro: o realismo jurídico pode ser lido como uma espécie de positivismo fático, empiricamente mais radical (com vieses psicologistas, sociologistas, etc.) e pessimista quanto a critérios públicos de normatividade. Em sua genealogia, também está o direito que se "põe" como fato social. Contudo, desloca-se o momento constitutivo do direito para a decisão judicial para o tipo de eficácia que assume no caso concreto.

Décimo segundo: para a Crítica Hermenêutica do Direito, a questão não é compreender o juspositivismo em suas características superficiais, mas, sim, em seus elementos constitutivos de natureza filosófica. O intento é buscar compreender o substrato filosófico do paradigma e que em alguma medida aparece em todas as suas expressões historicamente situadas. Por exemplo, observa-se que uma das características fundantes do juspositivismo é o relativismo e isto se manifesta de modo diverso na Escola da Exegese e no normativismo kelseniano, em que a decisão é entendida como um ato de vontade (no plano da aplicação, é claro, e não no plano do cientista do Direito). Ademais, pode-se pensar que isto persiste na contemporaneidade com 
o reconhecimento da discricionariedade, característica presente, rigorosamente, em todas as posturas e teorias positivistas.

Para concluir: não é possível servir a vários senhores da ciência ao mesmo tempo. Trata-se de uma opção paradigmática, o que acarreta uma impossibilidade de misturar, por exemplo, posturas ainda assentadas no esquema sujeito-objeto (em menor ou maior grau) e posturas antiepistemológicas. Definitivamente, hermenêutica não é teoria da argumentação, do mesmo modo que verdade não é consenso. Não é possível lançar mão tão somente das "partes nobres" de cada teoria (ou paradigma), descartando as insuficiências. Mas, atenção: a hermenêutica não afasta a epistemologia. Entretanto, o que não é possível fazer é confundir os níveis nos quais nos movemos. A separação entre o epistemológico e o nível concreto não é o mesmo que dividir o transcendental e o empírico. Em muitos momentos, a hermenêutica introduz o elemento epistemológico, se assim se quiser dizer. A posição hermenêutica não pretende eliminar procedimentos. Ela já sempre compreende essa circunstância, porque é capaz de analisar filosoficamente os elementos da pré-compreensão.

Ou seja, quando explicito o (já) compreendido, esse processo se dá no nível lógicoargumentativo, e não filosófico. E, insista-se: filosofia não é lógica. Esse "proceder epistemológico" é antecipado; não se confunde com o próprio conhecimento. Pela hermenêutica, fazemos uma fenomenologia do conhecimento. Não é uma coisa concreta. É, sim, a descrição da autocompreensão que opera na compreensão concreta. Na explicitação é que haverá o espaço de uma teoria do conhecimento.

Uma hermenêutica jurídica capaz de intermediar a tensão inexorável entre o texto e o sentido do texto não pode continuar a ser entendida como uma teoria ornamental do direito, que sirva tão somente para colocar "capas de sentido" aos textos jurídicos. No interior da virtuosidade do círculo hermenêutico, o compreender não ocorre por dedução. Consequentemente, o método (o procedimento discursivo) sempre chega tarde, porque pressupõe saberes teóricos separados da "realidade". Antes de argumentar, o intérprete já compreendeu.

\section{REFERÊNCIAS DAS FONTES CITADAS}

ALEXY, Robert. Teoria de la Argumentación Jurídica. Teoría del Discurso Racional como Teoria de la Fundamentación Jurídica. Madrid, CEPC, 1997.

BARROSO, Luis Roberto; BARCELLOS, Ana Paula de. O Começo da história: a nova interpretação constitucional e o papel dos princípios no direito brasileiro. Rio de Janeiro: Renovar, 2003.

BULOS, Uadi L. Manual de Interpretação Constitucional. São Paulo: Saraiva, 1997.

CAPPELETTI, Mauro. Juízes legisladores? Porto Alegre: Fabris, 1993. 
DASCAL, Marcelo. Interpretação e compreensão. Tradução de Marcia Heloisa Lima da Rocha. São Leopoldo, Unisinos, 2006. DELMAS-MARTY, Mirreile. Por um Direito Comum. São Paulo: Martins Fontes, 2004.

DINIZ, Maria Helena. Compêndio de Introdução à Ciência do Direito. São Paulo: Saraiva, 1998.

DOS SANTOS, Ernane Fidélis. Manual de Direito Processual Civil. Vol. 1. 11. ed. São Paulo: Saraiva, 2006.

DWORKIN, Ronald. Law's Empire. Londres: Fontana Press, 1986.

DWORKIN. Taking rights seriously. Cambridge: Harvard University Press, 1978.

GADAMER, Hans-Georg. Verdade e Método I: traços fundamentais de uma hermenêutica filosófica. 6. ed. Petrópolis: Vozes, 2004.

GADAMER. Verdade e Método Il: complementos e índices. 6. ed. Petrópolis: Vozes, 2004.

GADAMER. Wahrheit und Methode I: Grundzüge einer philosophischen Hermeneutik. Tübingen: J.C.B. Mohr (Paul Siebeck), 1990.

GADAMER. Wahrheit und Methode II: Ergänzungen Register. Tübingen: J.C. B. Mohr (Paul Siebeck), 1993.

GRONDIN, Jean. Hermenêutica. Tradução de Marcos Marcionilo. São Paulo: Parábola Editorial, 2012.

GÜNTHER, Klaus. Teoria da Argumentação no Direito e na Moral: justificação e aplicação. São Paulo, Landy, 2004.

HABERMAS, Jürgen. Faktizität und Geltung. Beiträge zur Diskurstheorie des Rechts und des demokratischen Rechsstaats. Frankfurt am Main, Suhrkamp, 1992.

HEIDEGGER, Martin. Sein und Zeit. 17. ed. Tübingen: Max Niemayer, Verlag Tübingen, 1993.

HEIDEGGER. Ser e Tempo. Vol. I e II. 5. ed. Petrópolis, Vozes, 1995.

LEAL, Rogério Gesta. O Estado-Juiz na Democracia Contemporânea - uma perspectiva procedimentalista. Porto Alegre: Livraria do Advogado, 2007.

MARINONI, Luiz Guilherme. O STJ como Corte de Precedentes: recompreensão do sistema processual da Corte Suprema. São Paulo: Revista dos Tribunais, 2013.

MARINONI; MITIDIERO, Daniel; ARENHART, Sérgio Cruz. O novo processo civil. São Paulo: Revista dos Tribunais, 2015.

MARINONI; ARENHART, Sérgio Cruz; MITIDIERO, Daniel. Novo Código de Processo Civil comentado. São Paulo: Revista dos Tribunais, 2015.

MORESO, J. J. La indeterminación del Derecho y la interpretación de la Constitución. Madrid: CEC, 1997.

NAGEL, Thomas. The view from nowhere. Oxford: Oxford University Press, 1986.

NEVES, Antonio Castanheira. O actual problema metodológico da interpretação jurídica - I. Coimbra, Coimbra Editora, 2003.

NIETO, Alejandro. El arbítrio judicial. Barcelona: Ariel, 2000.

PEREIRA, Caio Mário da Silva. Instituições de Direito Civil, volume I. 12. ed. Forense, 1990.

PORTANOVA, Rui. Princípios do Processo Civil. 3 ed. Porto Alegre: Livraria do Advogado, 1999.

STEIN, Ernildo. Aproximações sobre hermenêutica. 2. ed. Porto Alegre: Edipucrs, 2010.

STRECK, Lenio Luiz. Verdade e Consenso: Constituição, hermenêutica e teorias discursivas. 6. ed. São Paulo: Saraiva, 2017. 
STRECK, Lenio Luiz. Hermenêutica Jurídica e(m) Crise. 11. ed. Porto Alegre, Livraria do Advogado, 2013.

STRECK, Lenio Luiz. Jurisdição Constitucional e Decisão Jurídica. 4. ed. São Paulo: Revista dos Tribunais, 2014.

STRECK, Lenio Luiz. Precedentes Judiciais e Hermenêutica: o sentido da vinculação no CPC/2015. Salvador: Editora JusPodivm, 2018.

STRECK, Lenio Luiz. Processo Judicial como Espelho da Realidade? Notas Hermenêuticas à Teoria da Verdade em Michele Taruffo. Sequência, v. 37, p. 115-136, 2016.

STRECK, Lenio Luiz. Dicionário de hermenêutica: quarenta temas fundamentais da Teoria do Direito à luz da Crítica Hermenêutica do Direito. Belo Horizonte: Casa do Direito, 2017.

TAYLOR, Charles. Philosophical Arguments. New York: Harvard University Press, 1995.

TOURINHO FILHO, Fernando da Costa. Processo Penal. 23. ed. São Paulo: Saraiva. 2002.

ZACCARIA, G; VIOLA, F. Diritto e interpretazzione: Lineamenti di una ermeneutica del diritto. Roma/Bari: Laterza, 2001.

RECEBIDO EM: $17 / 06 / 2020$

APROVADO EM: 28/07/2020 